\title{
Genome and Metagenome of The Phytophagous Gall-Inducing Mite Fragariocoptes Setiger (Eriophyoidea): Are Symbiotic Bacteria Responsible For Gall-Formation?
}

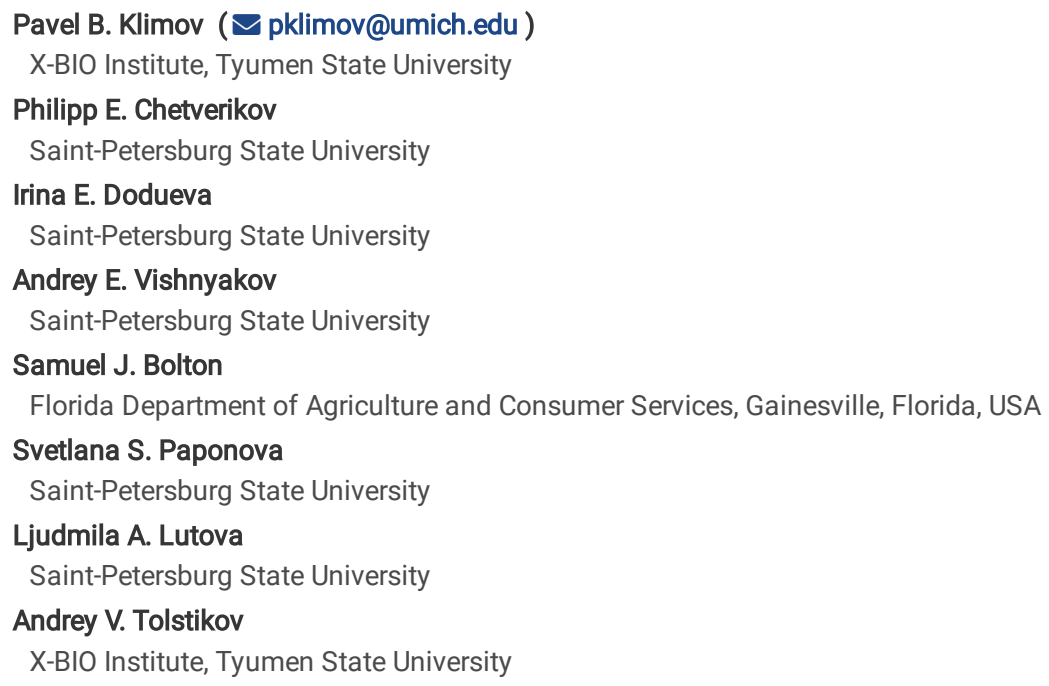




\section{Abstract}

Eriophyoid mites represent a hyperdiverse, phytophagous lineage with an unclear phylogenetic position. These mites have succeeded in colonizing nearly every seed plant species, and this evolutionary success was in part due to the mites' ability to induce galls in plants. A gall is a unique niche that provides the inducer of this modification with vital resources. The exact mechanism of gall formation is still not understood, even as to whether it is endogenic (mites directly cause galls) or exogenic (symbiotic microorganisms are involved). Here we (i) investigate the phylogenetic affinities of eriophyoids and (ii) use comparative metagenomics to test the hypothesis that the endosymbionts of eriophyoid mites are involved in gall-formation. Our phylogenomic analysis robustly inferred eriophyoids as closely related to Nematalycidae, a group of deep-soil mites belonging to Endeostigmata. Our comparative metagenomics, fluorescence in situ hybridization, and electron microscopy experiments identified two candidate endosymbiotic bacteria shared across samples, however, it is unlikely that they are gall-inducers (morphotype1: novel Wolbachia, morphotype2: possibly Agrobacterium tumefaciens). We also detected an array of plant pathogens associated with galls that may be vectored by the mites; a mite pathogenic virus (Betabaculovirus) has the potential to be used in the biocontrol of agricultural pests.

\section{Introduction}

Eriophyoid mites (four-legged mites, gall mites) represent an ancient lineage of common and widely distributed microscopic plant symbionts, with 4,400 nominal species primarily associated with ferns, gymnosperms and angiosperms ${ }^{1,2}$. Some of these mites are of agricultural importance, damaging host plants through feeding, gall-formation, and vectoring plant pathogens ${ }^{3-6}$. The ability to induce galls in their plant hosts is the most distinctive feature of eriophyoid mites. Galls create a unique niche that ensures the survival and sustainable population growth of mites through their manipulation of the host plant $^{2}$. Many species of eriophyoid mites are gall-forming, indicating that gall-inducement may be a key innovation, enabling these mites to colonize many terrestrial seed plant species. Gall-forming ability is an evolutionarily labile trait and a possible driver of mite speciation ${ }^{7}$. Different mite species, including non-gall-formers and those that produce different types of galls, can co-exist on a single plant host. Therefore, both host specificity and habitat partitioning via gall-inducement effectively increase eriophyoid species richness ${ }^{7}$.

Molecular mechanisms of gall-inducement are well known in bacteria ${ }^{8}$. However, in metazoan organisms, especially in mites and other arthropods, the exact nature of gall-formation is not well understood ${ }^{9-13}$. In many phytopathogenic bacteria, gall-formation ability is attributed to the production of cytokinins; these compounds, in the presence of auxin, lead to cell division and proliferation of plant tissue, resulting in the formation of galls or tumors ${ }^{14-16}$. Auxin-like and cytokinin-like activities have been detected in the salivary gland secretions of mites, and these phytohormones are delivered to the host plant during feeding ${ }^{17}$. High levels of auxins and cytokinins have been detected in mite-induced gall tissues ${ }^{18}$. It is likely that mites, like gall-forming insects, nematodes, and fungi, produce cytokinins endogenously via the regular tRNA-ipt pathway, which is present in all cellular organisms except for Archaea ${ }^{10,19,20}$. Gallinducing organisms may also inject effector proteins (produced endogenously) such as CLE and CEP-peptides into their plant host, which are plant hormone mimics ${ }^{21,22}$. However, associated bacteria may also enhance the production of phytohormones by gall-inducing arthropods ${ }^{23,24}$. Here we test the latter hypothesis of an exogenous mechanism of gall-inducement ${ }^{23,24}$. Our assumption is that if bacteria play an important role in gall-formation, a common bacterial species (gall-inducer) must exist across galls harboring the same mite species. Alternatively, if no common bacterial species is found across conspecific mite samples, then mite-specific bacteria are unlikely to cause galls or enhance their production. A key to this approach is accurate estimation of relative and absolute abundances of mite-associated microorganisms.

The phylogenetic position of Eriophyoidea on the tree of life is also a long-standing and contentious issue. One hypothesis places them near Nematalycidae (Acariformes: Endeostigmata) ${ }^{25,26}$, a deep-soil, basal acariform lineage, whereas another hypothesis places them within Eupodina (Trombidiformes) ${ }^{25,27}$, a relatively derived lineage that includes inhabitants of soil and plants. Definitive resolution of this question is key for understanding the basal relationships and early ecology of acariform mites, one of the oldest known terrestrial lineages ${ }^{28,29}$. Inferring an accurate position for Eriophyoidea is essential to ensure the stability of higher-level mite classification, since the two major mite divisions, Trombidiformes and Acariformes, are effectively undiagnosable without knowing the true position of Eriophyoidea. However, phylogenomic-scale datasets have only recently become available to answer this question.

Here we test the two aforementioned hypotheses on exogenous gall-inducement and the phylogenetic position of Eriophyoidea using deep, short read sequencing of the mite Fragariocoptes setiger, which causes distinctive galls on leaves of the green strawberry (Fragaria viridis) in Europe (Fig. 1). First, we used several metagenomic analyses to characterize the microbiome composition of the mite from two independent samples. We then used these data to find a common bacterial species, a potential bacterial gall-inducer. We combined this metagenomic evidence with FISH-hybridization experiments and TEM microscopy. Second, we assembled a whole genome of $F$. setiger and inferred a phylogenomic tree of acariform mites, including two novel genomes of basal endeostigmatan taxa. With respect to the hypothesis on gall inducement, other interesting research directions, like searching for genomic signatures of gallinducement in mites, will be addressed in separate papers using additional evidence (for example, comparative genomics using a closely related non-gall inducing mite species, namely Fragariocoptes ambulans).

\section{Results}

Genome. The mite genomic assembly was 40,873,958 bp in size, had 3,581 contigs - N50=31,600 (Table 1) -and 3,056 predicted and annotated genes. Metatranscriptomic assembly $(39,862,892$ bp, $N 50=1,643$ for contigs $\geq 500$ bp only) had a total of 145,220 contigs; of these, 22,669 could be aligned back to the mite genomic assembly (Supplementary Table S1). BUSCO estimated that the mite genome is $58.7-77.0 \%$ complete. Specifically, BUSCO4 (arachnida_odb10, 2,934 genes) identified 1,724 (58.7\%) complete, 56 (1.9\%) fragmented, and 1154 (39.4\%) missing genes. Of the genes in the former category 1,673 (57.0\%) were single-copy and 51(1.7\%) were duplicated. BUSCO3 (arthropoda_odb9, 1,066 genes) identified the following: complete: 821 (77.0\%) [single-copy:805 (75.5\%), duplicated:16 (1.5\%)], fragmented: 41(3.8\%), missing: 204(19.2\%) genes. The mitochondrial genome had the standard set of 
protein-coding genes, rDNAs, and tRNAs. Mitochondrial gene arrangement (GenBank accession JAIFTH000000000) was similar to that of other known eriophyoid mites, except the 16S-2S rDNA gene segment was inverted in Fragariocoptes (lineage Phytoptidae), which corresponds to the ancestral chelicerate order, while in other known eriophyoids (all belong to the lineage Eriophyidae s.l.) this segment is not inverted.

Table 1. Basic statistics for three assemblies of the mite Fragariocoptes setiger and its microbiome.

\begin{tabular}{|llll|}
\hline & Metagenome* & Metatranscriptome* & Mite genome \\
\hline Contigs number (N) & 70,345 & 31,089 & 3,581 \\
\hline Total contig size (bp) & $139,253,250$ & $39,862,892$ & $40,873,958$ \\
\hline Longest contig (bp) & 423,970 & 18,766 & 182,071 \\
\hline Mean contig length (bp) & $1,979.58$ & $1,282.22$ & $11,414.12$ \\
\hline Median contig length (bp) & 757 & 826 & 3,603 \\
\hline Standard deviation of contig length (bp) & $7,685.98$ & $1,167.73$ & $18,445.63$ \\
\hline Contig L50 (N) & 2,683 & 6,522 & 370 \\
\hline Contig N50 (bp) & 6,218 & 1,643 & 31,600 \\
\hline Contig L75 (N) & 19,995 & 15,263 & 834 \\
\hline Contig N75 (bp) & 1,102 & 839 & 15,183 \\
\hline Contig L90 (N) & 45,528 & 23,782 & 1,445 \\
\hline Contig N90 (bp) & 641 & 599 & 6,110 \\
\hline Average coverage & 265.81 & 192.21 & $4,568.12$ \\
\hline Median coverage & 6.44 & 10.57 & $2,480.21$ \\
\hline Standard deviation of coverage & $3,185.71$ & $4,161.95$ & $6,778.21$ \\
\hline Total GC content (\%) & $54.43 \%$ & $47.38 \%$ & $43.18 \%$ \\
\hline Average contig GC content (\%) & $57.27 \%$ & $47.66 \%$ & \\
\hline
\end{tabular}

* - for contigs $\geq 500$ bp only.

Phylogenetic analyses. Our phylogenomic analysis shows strong support for Eriophyoidea being part of Endeostigmata (Fig. 2) (SH-aLRT support=100\%, bootstrap support=99\%) (Table 2: detailed mite systematics). Particularly, Eriophyoidea was sister to Nematalycidae (SH-aLRT support=100\%, bootstrap support=100\%). Inspecting the source gene alignment matrices revealed that the Endeostigmata+Eriophyoidea grouping was supported by many molecular synapomorphies (Fig. 3a-b). Endeostigmata (including Eriophyoidea) was inferred as sister to Sarcoptiformes (SH-aLRT support=93.2\%, bootstrap support=91\%). Topology based on the non-curated matrix was essentially the same (not reported further).

Table 2. GenBank/SRA accession ids and taxonomic classification of taxa used to infer the position of eriophyoid mites on the tree of life. SRA short read data were assembled as part of this project. G=genome, T=transcriptome; "-"=no name at this level of taxonomic hierarchy. 


\begin{tabular}{|c|c|c|c|}
\hline Species & Type & Accession & Class:Superorder:Order:Suborder:Infraorder:Hyporder:Family \\
\hline $\begin{array}{l}\text { Limulus } \\
\text { polyphemus }\end{array}$ & G & GCF_000517525.1 & Xiphosura:-:-:-:-:Limulidae \\
\hline Ixodes scapularis & G & GCF_002892825.2 & Arachnida:Parasitiformes:Ixodida:-:-:-:Ixodidae \\
\hline $\begin{array}{l}\text { Galendromus } \\
\text { occidentalis }\end{array}$ & G & GCF_000255335.1 & Arachnida:Parasitiformes:Mesostigmata:Monogynaspida:Gamasina:Dermanyssiae:Phytoseiidae \\
\hline Varroa destructor & G & GCF_002443255.1 & Arachnida:Parasitiformes:Mesostigmata:Monogynaspida:Gamasina:Dermanyssiae:Varroidae \\
\hline Varroa jacobsoni & G & GCF_002532875.1 & Arachnida:Parasitiformes:Mesostigmata:Monogynaspida:Gamasina:Dermanyssiae:Varroidae \\
\hline $\begin{array}{l}\text { Dermanyssus } \\
\text { gallinae }\end{array}$ & G & GCA_003439945.1 & Arachnida:Parasitiformes:Mesostigmata:Monogynaspida:Gamasina:Dermanyssiae:Dermanyssidae \\
\hline $\begin{array}{l}\text { Tropilaelaps } \\
\text { mercedesae }\end{array}$ & G & GCA_002081605.1 & Arachnida:Parasitiformes:Mesostigmata:Monogynaspida:Gamasina:Dermanyssiae:Laelapidae \\
\hline $\begin{array}{l}\text { Osperalycus } \\
\text { tenerphagus }\end{array}$ & G & JAGGCA000000000 & Arachnida:Acariformes:Sarcoptiformes:Endeostigmata:Nematalycina:-:Nematalycidae \\
\hline Speleorchestes & G & JAGHQN000000000 & Arachnida:Acariformes:Sarcoptiformes:Endeostigmata:Bimichaliida:-:Nanorchestidae \\
\hline Aceria tosichella & $\mathrm{T}$ & GGYP00000000.1 & Arachnida:Acariformes:Sarcoptiformes:Endeostigmata:Eriophyoidea:Eriophyidae \\
\hline $\begin{array}{l}\text { Fragariocoptes } \\
\text { setiger }\end{array}$ & G & JAIFTH000000000 & Arachnida:Acariformes:Sarcoptiformes:Endeostigmata:Eriophyoidea:Phytoptidae \\
\hline $\begin{array}{l}\text { Brevipalpus } \\
\text { yothersi }\end{array}$ & G & GCA_003956705.1 & Arachnida:Acariformes:Trombidiformes:Prostigmata:Eleutherengona:Raphignathina:Tenuipalpidae \\
\hline $\begin{array}{l}\text { Tetranychus } \\
\text { urticae }\end{array}$ & G & GCF_000239435.1 & Arachnida:Acariformes:Trombidiformes:Prostigmata:Eleutherengona:Raphignathina:Tetranychidae \\
\hline $\begin{array}{l}\text { Leptotrombidium } \\
\text { deliense }\end{array}$ & G & GCA_003675905.1 & Arachnida:Acariformes:Trombidiformes:Prostigmata:Anystina:Parasitengona:Trombiculidae \\
\hline $\begin{array}{l}\text { Dinothrombium } \\
\text { tinctorium }\end{array}$ & G & GCA_003675995.1 & Arachnida:Acariformes:Trombidiformes:Prostigmata:Anystina:Parasitengona:Trombidiidae \\
\hline $\begin{array}{l}\text { Hypochthonius } \\
\text { rufulus }\end{array}$ & G & GCA_000988845.1 & Arachnida:Acariformes:Sarcoptiformes:Oribatida:Enarthronota:-:Hypochthoniidae \\
\hline $\begin{array}{l}\text { Platynothrus } \\
\text { peltifer }\end{array}$ & G & GCA_000988905.1 & Arachnida:Acariformes:Sarcoptiformes:Oribatida:Desmonomata:Nothrina:Crotoniidae \\
\hline \multirow{2}{*}{$\begin{array}{l}\text { Alaskozetes } \\
\text { antarcticus }\end{array}$} & \multirow[t]{2}{*}{$\mathrm{T}$} & SRR6451453.1, & \multirow[t]{2}{*}{ Arachnida:Acariformes:Sarcoptiformes:Oribatida:Desmonomata:Brachypylina:Ameronothridae } \\
\hline & & SRR6451454.1 & \\
\hline Hermannia gibba & $\mathrm{T}$ & SRR4039019.1 & Arachnida:Acariformes:Sarcoptiformes:Oribatida:Desmonomata:Nothrina :Hermanniidae \\
\hline $\begin{array}{l}\text { Achipteria } \\
\text { coleoptrata }\end{array}$ & G & GCA_000988765.1 & Arachnida:Acariformes:Sarcoptiformes:Oribatida:Desmonomata:Brachypylina:Achipteriidae \\
\hline $\begin{array}{l}\text { Steganacarus } \\
\text { magnus }\end{array}$ & G & GCA_000988885.1 & Arachnida:Acariformes:Sarcoptiformes:Oribatida:Mixonomata:-:Steganacaridae \\
\hline $\begin{array}{l}\text { Tyrophagus } \\
\text { putrescentiae }\end{array}$ & G & GCA_012066115.1 & Arachnida:Acariformes:Sarcoptiformes:Oribatida:Desmonomata:Astigmata:Acaridae \\
\hline Psoroptes ovis & G & GCA_002943765.1 & Arachnida:Acariformes:Sarcoptiformes:Oribatida:Desmonomata:Astigmata:Psoroptidae \\
\hline Sarcoptes scabiei & G & GCA_000828355.1 & Arachnida:Acariformes:Sarcoptiformes:Oribatida:Desmonomata:Astigmata:Sarcoptidae \\
\hline $\begin{array}{l}\text { Dermatophagoides } \\
\text { farinae }\end{array}$ & G & GCA_002085665.2 & Arachnida:Acariformes:Sarcoptiformes:Oribatida:Desmonomata:Astigmata:Pyroglyphidae \\
\hline D. pteronyssinus & G & GCF_001901225.1 & Arachnida:Acariformes:Sarcoptiformes:Oribatida:Desmonomata:Astigmata:Pyroglyphidae \\
\hline $\begin{array}{l}\text { Euroglyphus } \\
\text { maynei }\end{array}$ & G & GCA_002135145.1 & Arachnida:Acariformes:Sarcoptiformes:Oribatida:Desmonomata:Astigmata:Pyroglyphidae \\
\hline
\end{tabular}

Mapping reads on reference genes of known gall-inducers (Gall-ID). A SRST2/Gall-ID analysis identifies gall-inducing bacteria by mapping reads to a reference database of select genes having close similarities or belonging to known gall-inducing bacteria. A single OTU of known gall-inducing bacterium (Agrobacterium tumefaciens, nucleotide identity=99.5-100\%) was found in both samples. However, a tumor-inducing Ti-plasmid, encoding loci responsible for the formation of galls, was only partially recovered. Some but not all of these genes were detected in sample 1, particularly the nopaline permease ATPbinding protein gene and a substantial portion of Type VI secretion system components (Table 3). Sample 2 lacked any loci encoded on Ti-plasmids (Table 3 ). In addition, Rhodococcus fascians, with the 16S gene having a $99.7 \%$ similarity to GenBank sequences, was detected in sample 2 only; in sample 1 , a different Rhodococcus OTU was present at low abundance (Table 3). Other known gall-inducing bacteria (Pseudomonas savastanoi pv. phaseolicola \& glycinea, 
Rhizobium rubi, Erwinia herbicola) were not detected; they only had distant matches to taxa from our datasets (Table 3). Validation of these results via read assembly

Table 3. NGS read mapping onto known reference genes of gall-inducing bacteria in Gall-ID. Validation was done by BLAST searches of assembled contigs

sample gene Gall-ID reference contig len1 depth diffs diverg ref.len MAF read.

\section{Sample 1 and 2}

\begin{tabular}{|c|c|c|c|c|c|c|c|c|c|}
\hline S1 & $16 S$ & 20_rRNA16s_rRNA16s_21 (Rhodococcus fascians) & 99.7 & 1156.5 & $85 s, 6 i$ & 5.55 & 1532 & 0.50 & $0.16 \epsilon$ \\
\hline S2 & $16 S$ & 20_rRNA16s_rRNA16s_21 (Rhodococcus fascians) & 99.9 & 4807.8 & $39 \mathrm{~s}, 2 \mathrm{i}$ & 2.55 & 1532 & 0.50 & 3.587 \\
\hline S1 & $16 S$ & 0_16S_Agrobacterium_tumefaciens_WRT31_198 & 100.0 & 1835.6 & $12 s$ & 0.84 & 1437 & 0.49 & $0.24 \varepsilon$ \\
\hline S2 & $16 S$ & 0_16S_Agrobacterium_tumefaciens_strain_MEJ076_65 & 100.0 & 2818172.0 & $6 s$ & 0.42 & 1437 & 0.49 & 1.975 \\
\hline S1 & $16 S$ & 0_16S_Pseudomonas_savastanoi_pv._phaseolicola_1448A_1 & 100.0 & 4612.1 & $20 s$ & 1.30 & 1539 & 0.46 & $0.66 \varepsilon$ \\
\hline S2 & $16 S$ & 0_16S_Pseudomonas_savastanoi_pv._glycinea_str._race_4_7 & 97.6 & 274.8 & $34 \mathrm{~s}, 37 \mathrm{~h}$ & 2.26 & 1539 & 0.47 & 0.201 \\
\hline
\end{tabular}

\section{Sample 1 only}

\begin{tabular}{|c|c|c|c|c|c|c|c|c|c|}
\hline S1 & tssC40 & 39_tssC40_Agrobacterium_tumefaciens_WRT31_19 & 100.0 & 43.8 & $13 \mathrm{~s}$ & 0.93 & 1395 & 0.31 & $0.00 \leftleftarrows$ \\
\hline S1 & $\operatorname{tag} \mathrm{H}$ & 33_tagH_Agrobacterium_tumefaciens_WRT31_13 & 100.0 & 39.0 & $5 s$ & 0.42 & 1200 & 0.05 & $0.00<$ \\
\hline S1 & $\operatorname{tag} J$ & 34_tagJ_Agrobacterium_tumefaciens_WRT31_15 & 100.0 & 35.8 & $10 \mathrm{~s}$ & 1.22 & 822 & 0.11 & $0.00<$ \\
\hline S1 & tssC41 & 40_tssC41_Agrobacterium_tumefaciens_WRT31_22 & 100.0 & 33.4 & $1 \mathrm{~s}$ & 0.07 & 1482 & 0.10 & $0.00<$ \\
\hline S1 & tssG & 44_tssG_Agrobacterium_tumefaciens_WRT31_22 & 100.0 & 29.2 & $3 s$ & 0.30 & 1005 & 0.13 & $0.00<$ \\
\hline S1 & $\operatorname{tag} \mathrm{F}$ & 32_tagF_Agrobacterium_tumefaciens_WRT31_8 & 100.0 & 27.6 & $15 s$ & 1.06 & 1410 & 0.36 & $0.00 乏$ \\
\hline S1 & tssE & 42_tssE_Agrobacterium_tumefaciens_WRT31_15 & 100.0 & 24.4 & $1 \mathrm{~s}$ & 0.20 & 510 & 0.07 & 0.001 \\
\hline S1 & nocP & 14_nocP_Agrobacterium_tumefaciens_strain_S2_52 & 53.9 & 9.8 & $39 s, 1 i, 272 h$ & 12.26 & 590 & 0.50 & $0.00 c$ \\
\hline S1 & tssF & 43_tssF_Agrobacterium_tumefaciens_GW4_16 & 62.1 & 3.9 & $87 s, 676 h$ & 7.87 & 1782 & 0.00 & $0.00 c$ \\
\hline S1 & tssk & 48_tssK_Agrobacterium_sp._H13-3_3 & 100.0 & 40.2 & $1 \mathrm{~s}$ & 0.08 & 1341 & 0.13 & 0.005 \\
\hline S1 & tssA & 37_tssA_Agrobacterium_sp._H13-3_2 & 100.0 & 31.6 & $3 s$ & 0.29 & 1040 & 0.11 & $0.00 \leftleftarrows$ \\
\hline S1 & tssD & 41_tssD_Agrobacterium_sp._H13-3_2 & 100.0 & 31.6 & & 0.00 & 477 & 0.08 & 0.001 \\
\hline S1 & $\operatorname{tag} \mathrm{E}$ & 31_tagE_Agrobacterium_sp._H13-3_3 & 100.0 & 28.6 & $4 \mathrm{~s}$ & 0.49 & 810 & 0.09 & 0.002 \\
\hline S1 & tssL & 49_tssL_Agrobacterium_sp._H13-3_3 & 99.9 & 27.7 & $7 s, 1 i$ & 0.46 & 1512 & 0.17 & $0.00 \leftleftarrows$ \\
\hline S1 & tssH & 45_tssH_Agrobacterium_sp._H13-3_3 & 100.0 & 26.8 & $10 \mathrm{~s}$ & 0.38 & 2670 & 0.27 & $0.00 \epsilon$ \\
\hline S1 & tssM & 50_tssM_Agrobacterium_sp._10MFCol1.1_16 & 100.0 & 31.3 & $22 s$ & 0.63 & 3480 & 0.36 & $0.01 c$ \\
\hline S1 & tssB & 38_tssB_Agrobacterium_sp._10MFCol1.1_19 & 100.0 & 31.2 & & 0.00 & 510 & 0.42 & 0.001 \\
\hline S1 & tssl & 47_2_Agrobacterium_sp._LC34_39 & 52.3 & 3.8 & $55 s, 625 h$ & 8.03 & 1310 & 0.50 & $0.00 c$ \\
\hline S1 & tssl & 46_1_Rhizobium_rubi_NBRC_13261_44 & 50.8 & 2.2 & $60 s, 748 h$ & 7.77 & 1520 & 0.50 & $0.00 c$ \\
\hline S1 & CysT & 7_CysT_Pseudomonas_savastanoi_pv._glycinea_str._B076_6 & 52.2 & 16.0 & $38 s, 393 h$ & 8.86 & 822 & 0.33 & $0.00 c$ \\
\hline S1 & ISEhe3 & 16_ISEhe3_ISEhe3_17 (Erwinia herbicola) & 50.2 & 6.7 & $35 \mathrm{~s}, 3 \mathrm{i}, 754 \mathrm{~h}$ & 4.59 & 1516 & 0.50 & $0.00 c$ \\
\hline
\end{tabular}

*=and other equivocal hits; $* *=$ Agrobacterium tumefaciens (CP032922.1), Agrobacterium sp. H13-3 (CP002249.1); ***= Agrobacterium sp. H13-3

(CP002249.1); ****= Agrobacterium tumefaciens (CP032922.1); \% id= percent identity (BLAST); aln. len=alignment length (BLAST); cov=coverage, k-mer based (assembled contig); diffs=differences between subject and reference (Gall-ID): s=snp, i=indel, $\mathrm{h}=\mathrm{hole}$; diverg=divergence; len $1=$ length coverage of reference (Gall-ID); MAF=Max MAF; na=assembly failed due to low read abundance; read.prop=read proportion*106; ref.len=Reference length.

followed by a BLAST search confirmed that these taxa actually belong to different species of mostly free-living bacteria (Table 3 ). In addition, these taxa were not present in both samples (Table 3). 
K-mer-based short read identification (Kraken). Kraken decomposes short reads into k-mers of size 35, which allows extremely fast read classification against a reference database. Our database included nearly all GenBank genomic sequences, except plants were represented by Fragaria vesca only. For the abundance threshold $\geq 0.0338 \%$ for all bacterial reads, 83 bacterial genera were identified in both samples, 28 in sample 1 and 76 in sample $2 ; 21$ genera were shared across the two samples (Fig. 1d). Among the 10 most abundant bacterial genera in each sample, two were shared: Cutibacterium and Wolbachia (Fig. 1e). Detailed taxonomic classification and abundance estimates for this and other threshold and no-threshold analyses are given in Supplementary Table S2, Supplementary Table S3, Supplementary Table S4 and Supplementary Fig. S1 and Supplementary Fig. S2.

Read mapping on marker genes. We identified OTUs shared across the two samples using mapping of raw metagenomic reads onto 14 marker, single-copy genes in SingleM ${ }^{30}$ (Supplementary Table S5). This method is largely taxonomy-independent and does not suffer from issues related to copy-number variation in ribosomal genes (16S, 23S), plasmids, and transposable elements. This analysis identified 16 OTUs present in both samples. Of them, 3 OTUs were found at high abundances (percentages of reads are given in parentheses for samples 1 and 2, respectively): Wolbachia (67.47, 22.65\%), Sphingomonadaceae (12.72, 5.02\%), and Propionibacteriaceae (4.46, 7.03\%) (Fig. 3c). Remarkably, SingleM did not find Agrobacterium and Pseudomonas in sample 2, and therefore these genera are not present among the 16 OTUs.

Assembly intersection. To detect OTUs common to the two samples, the two NGS assemblies were intersected and shared contigs were classified using the BLAST nucleotide database (Fig. 3d). The following four most abundant species were shared between the two samples: Wolbachia sp. (92.07\%, 15.24\%), Cutibacterium acnes (3.96\%, 64.71\%), Burkholderia sp. (2.46\%, 0.96\%), Agrobacterium sp. (0.16\%, 0.37\%) (Fig. 3d). Two species (Diaphorobacter polyhydroxybutyrativorans, and Pseudomonas sp.) were only abundant in sample 1, and two other species (Cloacibacterium normanense and Pedobacter sp.) were only abundant in sample 2. All other species occurred at low abundances in both samples (Fig. 3d). In addition, a plant pathogenic bacterium, Xanthomonas campestris, was identified in both samples at a low abundance $(0.01 \%, 0.09 \%)$.

Non-bacterial taxa. Because non-bacterial taxa can also induce galls ${ }^{8}$, we conducted a brief exploratory survey of major viruses and fungi that can elicit gall symptoms in their plant hosts using raw Kraken results with the confidence score set to 0.1 (as in all analyses above) but without an abundance cutoff. In our samples, there were 62 genera of viruses, but Phytoreovirus (causes galls) was absent (Supplementary Table S4). The two most abundant viral genera were Pahexavirus $(0.0002 \%, 0.0012 \%)$, which was probably a Cutibacterium acnes phage, and Betabaculovirus $(0 \%, 0.0006 \%)$, which probably uses the mite as a host. Among gall-inducing Oomycota, we found Albugo laibachii at a perceptible abundance, especially in sample $2(0.036 \%$; for comparison, sample $1=$ $0.003 \%$ ) (Supplementary Table S4). The fungus Ustilago maydis (causing corn smut) was found at a very low abundance $(0.00006 \%$ and $0.00416 \%$ in samples 1 and 2, respectively; Supplementary Table S4).

Phytohormones and horizontal gene transfer. The annotated mite genomic assembly revealed no known bacterial/plant genes responsible for the production of phytohormones and enzymes involved in plant growth regulatory metabolism.

TEM observations. We found two endosymbiotic bacterial morphotypes. Morphotype 1 was globular (Fig. 4i-j), which is consistent with the Wolbachia morphology. However, unlike all known Wolbachia, this bacterium was extracellular (Fig. 4i-j). Morphotype 2 was rod-shaped and also extracellular (Fig. 4i,k-I). Both morphotypes were most often closely associated with mite cell-plasma membranes. There were three distinct localizations: (i) around gigantic parenchymal cells (forming the fat body) filled with what is presumably lipid or glycogen vesicles (Fig. 4l); (ii) around and inside the salivary glands (in both cases surrounding the salivary gland cells, rather being inside these cells); (iii) under the mite epidermis, between the cells of underlying tissues (muscles and the fat body) (Fig. 4i). Bacteria were not found in mite oocytes, inside the gut or gut lumen.

Fluorescence in situ hybridization. Abundant bacterial cells were detected inside mites using eubacterial (Fig. 4c, h), Agrobacterium tumefaciens-specific probes (Fig. 4b,d,g), and a combination of these probes (Fig. 4e). No-probe controls were also done (Fig. 4a,f). There was a substantial bacterial presence around the gigantic parenchymal cells (Fig. 4g,h), in intermuscular spaces of the body (Fig. 4d,e), and around the salivary glands (Fig. 4g,h).

\section{Discussion}

Our phylogenomic analysis robustly inferred Eriophyoidea as sister to Nematalycidae (Fig. 2), a group of deep-soil, vermiform mites belonging to Endeostigmata. This result is well-supported and provides nearly decisive evidence for the long-standing controversy about the phylogenetic position of Eriophyoidea, which could not be confidently placed within a major mite lineage (see detailed discussion in ${ }^{25,26}$ ). Previous molecular studies were ambiguous, either because of incongruences among different data partitions ${ }^{25}$, unusual relationships involving Astigmata ${ }^{31,32}$, or the lack of sequence data for noneriophyoid Endeostigmata ${ }^{31,33-35}$. A recent morphological analysis, however, identified several synapomorphies supporting the Eriophyoidea + Nematalycidae lineage ${ }^{26}$, which is in agreement with our result. By placing Eriophyoidea within Endeostigmata, our phylogenomic inference provides the stability for the highlevel classification of acariform mites.

Using comparative metagenomics, we also tested whether gall-inducement in the Fragariocoptes setiger system is of a bacterial nature. To find a potential gall-inducer, two independent metagenomes (sample 1 and 2; Fig. 1) of the gall-inducing mite were analyzed. We conducted several metagenomic analyses, each using a different methodology: Gall-ID (comparison with known gall-inducers), Kraken (k-mer-based classification using nearly the entire GenBank nucleotide data as the reference database), SingleM (comparison with 14 single-copy bacterial genes), and BLAST (classification of the intersection of the two metagenomic assemblies). Below we discuss the results of these analyses and then provide a synthesis of these data before giving concluding remarks.

Mapping reads of known gall-inducing bacteria in Gall-ID identified several potential candidates: Agrobacterium tumefaciens (99.8-100\% match for 16S in both samples) and Rhodococcus fascians (16S match 99.7\%, sample 2 only) (Table 3); there were also matches with Pseudomonas savastanoi and Erwinia herbicola, but these matches were not confirmed by validation analyses (Table 3). Agrobacterium tumefaciens is a common and widespread bacterium responsible for formation of crown galls in the rhizosphere of various plants, but only strains containing a tumor-inducing plasmid (Ti plasmid, pTi) are

Page 6/16 
virulent. We found no evidence for the presence of a complete Ti plasmid, especially its functionally important virulence genes Vir ${ }^{36}$. Other genes that may be associated with tumor-inducement pathways and encoded on the Ti plasmid ${ }^{37}$ were only found in sample 1: nopaline permease ATP-binding protein gene and a substantial portion of Type IV secretion system components (Table 3 ). However, these genes may be encoded on other plasmid types occurring in nonvirulent bacterial strains ${ }^{38}$. Because crucial components of the Ti plasmid that are functionally important for tumor-formation (Virgenes) are lacking and $A$. tumefaciens is commonly found on healthy plants, either externally ${ }^{39}$ or internally ${ }^{40}$, this bacterium probably does not use the classical Ti-plasmid inducement pathway in our system, but its role in gall inducement using a different pathway cannot be completely excluded (see also TEM microscopy and FISH experiments below). Rhodococcus OTUs with $97.7 \%$ (sample 1) and $99.9 \%$ (sample 2) identity to Rhodococcus fascians had unequal 16 S abundances $\left(0.18 \times 10^{-6}\right.$ and $3.58 \times 10^{-6}$ of all reads in samples 1 and 2, respectively). Given the very low abundance of Rhodococcus in both samples (Fig. 1 e) and a $2.1 \%$ difference in their 16S rDNA genes, we believe that it is unlikely that this bacterium has a biologically important role in our system. The genus $P$ seudomonas can colonize a wide range of ecological niches ${ }^{41}$; as a plant pathogen it can cause tumorous overgrowths (knots), cankers, foliar necrosis, and bacterial blight 42-45. Knot-inducing pathovars encode genes related to indole acetic acid, cytokinins, rhizobitoxine, bacteriophytochrome, and others ${ }^{42,46}$. Our Gall-ID analyses identified the $16 \mathrm{~S}$ gene of Pseudomonas savastanoi in both samples, albeit with mismatches with the reference sequences (Table 3 ). Validation of these data via a separate BLAST search did not confirm the presence of Pseudomonas savastanoi; instead, two different species were identified, $P$. yamanorum (CP012400.2) and P. sp. DHXJ03 (JN244973.1) in samples 1 and 2, respectively (Table 3). None of these species are known to induce galls. GallID also identified the ISEhe3 insertion element of Erwinia herbicola in sample 1 only (Table 3). This bacterium is a widespread epiphyte on many different plants, also occurring in other habitats, such as seeds, water, humans, and animals ${ }^{47}$. Several plant tumorigenic strains of $E$. herbicola have been identified; all carry a pPATH pathogenicity plasmid encoding virulence genes ${ }^{48}$. ISEhe3 and other insertion elements are also present on the plasmid of plant-pathogenic strains, which suggests that these elements could participate in the evolution of the pPATH plasmid ${ }^{48}$. Validation of these data yielded a $98.5 \%$ match with Erwinia persicina, a bacterium which is known to be plant pathogenic but not gall-inducing ${ }^{49}$. The ISEhe3 insertion element was not detected in sample 2 , indicating that Erwinia is probably not responsible for gall inducement in our system.

Among the 10 most abundant genera identified by Kraken in each sample, only two were shared: Wolbachia and Cutibacterium. The latter genus was represented by Cutibacterium acnes. This bacterium is associated with the human skin, and is a widespread contaminant of DNA extraction kits ${ }^{50}$; we consider its presence as a likely artefact. With respect to the well-known gall-inducers discussed above, our analysis showed highly uneven or low abundances in samples 1 and 2: Agrobacterium (11.64, 0.18\%), Pseudomonas (64.23, 1.34\%), Rhodococcus (0.06, 2.04\%), Erwinia (0.04, 0.05\%) (Supplementary Table S2; Fig. 1e). These data, therefore, agree with our conclusion that these bacteria (except probably Agrobacterium) do not play an important role in gall-formation in our system (see above). Below, we briefly discuss several other bacterial genera from our samples that have gall-inducing species. A novel species of Wolbachia was common among the two samples, occurring at $16.7 \%$ (sample 1) or 9.7\% (sample 2) of all bacterial reads (Fig. 1e; Supplementary Table S2). It has been hypothesized that Wolbachia is used by caterpillars of a leaf-mining moth to produce green islands in yellowing leaves, which act as sinks for nutrients ${ }^{51}$. Manipulation of cytokinin levels by the endosymbiotic bacterium was suggested as the cause of green-island formation ${ }^{24,51}$. However, the exact molecular mechanism is not known and co-phylogenetic evidence indicates that the correlation of Wolbachia and the 'green-island' phenotype is high but not absolute ${ }^{52}$. Wolbachia associated with root-feeding insects can lower plant defenses ${ }^{53}$, and mites may use this property to invade new host plants. Xanthomonas was found at low abundances, 0.4 and $1.7 \%$ of all bacterial reads in samples 1 and 2, respectively. This bacterium interacts with the host plant by using a type III secretion system (T3SS) to secrete an array of effector proteins. Virulence factors include lytic enzymes that attack the plant's cell wall, in addition to proteases, amylases, cellulases and lipases that help lower the plant's defense mechanisms ${ }^{54}$. It would therefore be interesting to further explore whether eriophyoid mites can use associated bacteria, such as Xanthomonas or Pseudomonas, to suppress host plant defenses at early stages of plant colonization ${ }^{54,55}$, while bacteria can use mites to penetrate through the plant cell walls at the mite feeding site. Furthermore, the following four OTUs were identified by Kraken at low abundances, 0.00001-0.15\%: Paraburkholderia, Rhizobacter, Frankia, Phytoplasma (sample 2 only) (Supplementary Table S4). These bacterial genera include gall-inducing species ${ }^{56-60}$, with Phytoplasma being unique as it can replicate intracellularly both in plants and their insect vector hosts, while other bacteria can replicate only in plant cells ${ }^{60-62}$. Based on their extremely low and uneven abundances, it is unlikely that these OTUs are responsible for gall-formation in our system.

In addition to the above Gall-ID and Kraken analyses, we also ran SingleM (Fig. 3c) and assembly intersection analyses (Fig. 3d). These analyses returned similar but not identical results (Fig. 3c,d). First, unlike Gall-ID and Kraken, these analyses largely do not rely on existing taxonomy to identify OTUs shared across samples and, therefore, may be more accurate with respect to organisms having no sequence data in GenBank. Second, the differences can also be attributed to disparate underlying methodologies used by these analyses, data complexity, and the uneven coverages of the two datasets. For example, in Bacteria, rDNA may have multiple copies per genome (e.g., Agrobacterium), resulting in higher coverages, and therefore affecting both k-mer-based and assembly-based methods. The assembly of rDNA reads may also be positively biased due to rDNA sequence conservatism also affecting assembly-based methods. These issues are exaggerated if closely related species are present (e.g., Pseudomonas, Agrobacterium in our samples). Furthermore, k-mer-based (Kraken) and assembly-based methods may be affected by the presence of plasmids and mobile elements, which may have multiple copies in the genome (thus a species abundance can be overestimated) and may be shared across species (thus creating spurious classifications when based on reference sequence databases). Our SingleM analyses, relying on single-copy protein-coding genes, did not detect low abundance taxa, such as Agrobacterium and Pseudomonas, in sample 2 (Fig. 3c), while other analyses, using rDNA among other sequence data, were able to detect these taxa (Fig. 1e, Fig. 3d). In other words, differences between various metagenomic analyses conducted here are expected, and we consider our results to be complementary to each other.

A comparison of our metagenomic results, FISH and TEM microscopy suggests that Wolbachia was the only abundant OTU shared across the two samples. The substantial abundance of this bacterium points to a functional importance for its mite host. Some Wolbachia are known to be beneficial to nematode or insect hosts ${ }^{63}$ and it is likely that this is also the case here. Wolbachia is not known to induce galls but was suspected of manipulating cytokinin levels ${ }^{24,51}$ (see above). The Fragariocoptes endosymbiotic Wolbachia is a novel and very divergent species, with a substantial average nucleotide difference (20.7\%) with respect to other known Wolbachia. For this reason, it may have unexpected properties, including gall-inducement. Additional experiments would be required to 
confirm this hypothesis. Our FISH experiments and the metagenomic analyses (sample 1) suggested the presence of Agrobacterium tumefaciens (morphotype 2), which is a major inducer of crown galls (Fig. $4 b, d, e, g$ ). This is also an unexpected result since its intimate association with arthropod hosts has not been documented in the literature so far, except for a single study that provided experimental evidence that this bacterium can be vectored by an insect ${ }^{64}$. Both FISH and TEM microscopy identified a rod-shaped endosymbiotic, extracellular bacterium that characteristically surrounds gigantic parenchymatic mite cells and congregates in intermuscular spaces, especially around salivary gland cells (Fig. 4d,e,g,h,k,l). The abundance of this bacterium and its characteristic distribution inside the mite indicate a strong biological association with the mite. Gall-inducement by this bacterium cannot be excluded with data at hand, and further work is needed to evaluate this possibility. Given the incomplete Ti plasmid and the substantial abundance of Agrobacterium tumefaciens in sample 1 (see above), we cautiously suggest that a role of this bacterium in gall-formation in our system is unlikely and needs to be further evaluated. A similar conclusion of no bacterial involvement in gall formation has been recently made for insect gall inducers ${ }^{65}$

In conclusion, here we use comparative metagenomics to test the hypothesis suggesting that a bacterial symbiont can be involved in gall-inducement in eriophyoid mites using two independent samples from the mite Fragariocoptes setiger. We found a novel bacterial species of Wolbachia shared across all analyzed metagenomic samples of the gall-inducing mite. Another endosymbiotic extracellular, rod-shaped bacterium (morphotype 2, possibly Agrobacterium tumefaciens) was also detected, and based on its distribution inside the mite, it appears to form a biologically important association with the mite. Although we were able to demonstrate the presence of the two potential candidates we suggest that they role in gall-inducement is unlikely. In addition, we detected an array of plant pathogens that are associated with galls and may be vectored by the mite: Xanthomonas campestris, Rhodococcus fascians, Rhodococcus nr. olei, Erwinia nr. persicina, Clavibacter michiganensis (bacteria), Albugo laibachii (Oomycota), and Erysiphaceae (powdery mildews). Some mite-associated microorganisms (Xanthomonas, Pseudomonas, and Albugo laibachii) can use their host to penetrate through the plant cell walls at the mite feeding site. In return, these microorganisms can help the mite to suppress host plant defenses at early stages of plant colonization. Furthermore, we found a mite pathogenic virus, Betabaculovirus, which is a double-stranded DNA virus, that may have a potential use in the control of agricultural pests.

\section{Methods}

Samples. Sample 1. Russia: Novgorod Prov., right bank of Luga river, nr. Maluy Volochek village, 58.486544 N 30.338933 E, galls on leaves of Fragaria viridis, 14 Sept. 2018, about 80 adult mites. Sample 2. Russia: Leningrad Prov., Luzhsky District, 184m E Beloye Ozero [Beloye Lake], 58.808028 N, 30.487389 E, galls on leaves of Fragaria viridis, Aug 10 2019, about 1500 specimens obtained by alcohol washing. Collection of plant material was done with relevant institutional, national, and international guidelines and legislation. This collecting was done as part of cooperative agreement № 075-15-2020-922 (Ministry of Science and Higher Education of the Russian Federation) for a non-endangered, non-psychoactive species growing on public land outside of protected areas; no additional permissions and/or licenses are required for these samples as per paragraph 11 of the Forest Code of the Russian Federation (No. 200-FZ).

Nucleic acid extraction and sequencing. DNA/RNA extraction and Illumina next generation sequencing were performed as detailed in Supplementary Methods.

Genomic assembly, decontamination, annotation, phylogenomic analyses. Mite metagenomic assembly was done in MetaSPAdes v. $3.13 .0{ }^{66}$. It was decontaminated using MetaBat v. 2.12.167, BLAST, and Diamond ${ }^{68}$, and annotated in Maker v.2.31.10 ${ }^{69}$ using the mite transcriptome and Ecdysozoa UniProtKB / Swiss-Prot proteins for gene prediction. See detail in Supplementary Methods. The phylogenomic tree was inferred using amino acid sequence data in a Maximum Likelihood framework in IQ-TREE ${ }^{70}$ with alignment matrices prepared based on the BUSCO v.4 arachnida_odb10 database ${ }^{71}$ and custom utility scripts. See detail in Supplementary Methods.

Gall-ID. For identification of gall-inducing bacteria in samples 1 and 2 using raw reads, we used SRST2 ${ }^{72}$ and Gall-ID databases ${ }^{73}$, with the minimum gene coverage parameter set to $50 \%$ and maximum divergence parameter set to $10 \%$ : srst2 -input_pe \$input_file_reads_forward \$input_file_reads_reversed max_divergence 10 -min_coverage 50 -log -output \$out -gene_db \$input_file_gene_db -threads \$proc -report_all_consensus. Gall-ID databases have either functional genes known to be part of gall-inducement pathways or house-keeping genes (16S rDNA) that can be used to identify gall-inducing bacteria. Since the use of a majority rule consensus sequence (the Gall-ID default) is unreliable in the presence of multiple similar bacterial species, we also conducted validation of our Gall-ID results: (i) reads mapped on target genes in the Gall-ID databases were extracted (samtools fastq - 1 forward.fq - 2 reverse.fq -S singletons.fq -0 other.fq in.bam), (ii) and assembled in SPAdes (for PE reads: spades.py -1 forward.fq -2 reverse.fq -s singletons.fq -t \$proc; for SE reads: spades.py -s \$extracted.reads.fq -t \$proc -k 127), (iii) SPAdes contigs were then classified by BLAST.

K-mer-based metagenomic profiling. Taxonomic classification of raw reads was made by Kraken2 v.2.0.8 ${ }^{74}$. A custom 35-mer database was built from six standard Kraken databases (archaea, bacteria, fungi, human, protozoa, and viral) plus the genomes of Fragaria vesca (GenBank accession GCF_000184155.1), Albugo laibachii Nc14 (GenBank BioProject accession: PRJEA53219), Fragariocoptes setiger (JAIFTH000000000, assembled here), Wolbachia endosymbiont of Fragariocoptes setiger (JAHRAF000000000, assembled here) and the Illumina PhiX technical sequence. Taxonomic classification was done with a confidence scoring threshold value of 0.1 , which performed well in identifying Illumina PhiX technical sequences (not reported). In addition, this approach also substantially decreases the number of false positive classifications ${ }^{75}$. Using Kraken utilities scripts (KrakenTools), we converted standard Kraken report files to MetaPhIAn format and then combined these converted files as follows: kreport2mpa.py -r \$kraken_report -o \$kraken_report.mpa; combine_mpa.py -i kraken_report1.mpa,kraken_report2.mpa -o kraken.mpas.combined.txt. To estimate relative abundances, we also tried Bracken ${ }^{76}$, using the read length value as appropriate, $150 \mathrm{bp}$ (sample 1) and $250 \mathrm{bp}$ (sample 2). However, this analysis produced spurious results, e.g., the read proportion for Enterobacteriaceae were seemingly overestimated: 310.6 times (Salmonella) and 299.2 times (Escherichia) higher in sample 1 as compared to the Kraken data. Abundances of these taxa were also substantially overestimated in sample 2 . Since these unusually high abundances were not supported by any other analyses (Kraken, singleM, BLAST, see below), we do not report Bracken analyses here.

Our initial Kraken analysis yielded a large number of OTUs, suggesting that many reads were probably overclassified ${ }^{75}$. For example, there was a total of 1,124 genera, including 975 bacterial genera. We believe that such a large diversity is biologically unrealistic and we used a combination of Kraken confidence 
filtering $\left(0.1\right.$, see above) and an abundance cutoff $(\geq 0.0338 \%)$ as suggested in the literature ${ }^{75}$. For comparison, we also ran an analysis with a lower abundance cutoff ( $\geq 0.0005 \%)$.

To calculate the taxonomic intersection (shared OTUs in samples 1 and 2), bacterial genera with a fraction of reads $\geq 0.0338 \%$ at least in one sample were selected, and then these data were used to create Venn diagrams (OTU counts) and abundance heatmaps. For Bacteria, this analysis yielded a total of 83 genera in both samples and 21 genera in the sample intersection, which we consider biologically meaningful, and so we present this as our main result. These data were clustered based on Euclidean distances and visualized as heatmaps in TBTools ${ }^{77}$. For comparison, abundance heatmaps were also generated for all organisms using a lower abundance cutoff value ( $\geq 0.0005 \%)$, yielding 171 classified genera.

Identifying common OTUs across samples: Read mapping on marker genes. We identified OTUs shared across the two samples based on mapping of raw reads on 14 marker, single-copy genes in SingleM ${ }^{30}$. This is an assembly-free, largely taxonomy-independent approach. The use of a subset of single-copy genes eliminates issues associated with copy-number variation in ribosomal genes (16S, 23S), plasmids, and transposable elements. The following commands were used to create OTU tables from both samples, combine them and cluster OTUs: singlem pipe -forward $\$ f 1 . f q-$ reverse $\$ f 2 . f q-o t u \_t a b l e$ \$dna_tbl -threads \$proc; singlem summarise -input_otu_tables \$dna_tbl \$rna_tbl -output_otu_table dna_rna.combined.otu_table.csv; singlem summarise -input_otu_tables dna_rna.combined.otu_table.csv -cluster -clustered_output_otu_table clustered.otu_table.csv.

Unique representative sequences (used as "OTUs" in SingleM) shared across the two samples were filtered. This dataset was used to construct a heatmap (see the next subsection), where: (i) percentages of the average read counts across the 14 marker genes were used for each OTU in both samples; (ii) gene count, which is indicative of the data completeness, was recorded and visualized on the heatmap.

Identifying common OTUs across samples: Assembly intersection. Common OTUs present in the two NGS samples could also be identified via read assembly for each sample followed by assembly intersection. Intersection was done by standalone BLAST where sample 1 contigs were the query and sample 2 contigs were the subject. Matches having $\geq 98 \%$ similarity and bitscore $\geq 500$ were then classified by BLAST. OTUs having $>=96 \%$ similarity with GenBank nucleotide (nt) database were classified at the species level, while all other matches were classified at the genus level (top hits were reported in case of multiple matches). This approach generated a subset of contigs shared between the two assemblies, and these contigs were identified by their sequence similarity (not by taxonomic labels). This methodology effectively minimizes the effect of high misclassification rates due to incompleteness of the GenBank databases 78 . For each contig, read-based coverage was calculated in bbduk (bbmap.sh ref=\$ref in $1=\$ f 1$ in $2=\$ f 2$ covstats $=$ covstats.txt), and the number of mapped reads per classified OTUs were recorded. To minimize the influence of rDNA (which may have multiple copies per genome), plasmids, and mobile/transposable elements (which may occur in multiple species), BLAST results were checked and edited. Final read count data were normalized by calculating read percentages. It is important to emphasize that this procedure was done only for OTUs present in the intersection (so these data can only be interpreted in the context of the subset of OTUs present in both samples). Then these data were $\log _{2}$-transformed, and a heatmap was constructed in TBtools v.1.0 77 . In this heatmap, each OTU was labeled with (i) an intersection bitscore, which is indicative of the magnitude of common matches across the two metagenomic samples for a given OTU, and (ii) average percent identity with the closest GenBank matches. Clustering was done using Euclidean distances. We did this analysis using only bacterial taxa. Among fungi, some of which also can cause galls, we found only a single dominant taxon, the family Erysiphaceae (powdery mildews, which do not produce galls). Best matches were Cystotheca wrightii AB120747.1 (18S identity $=100 \%$ bitscore $=813$ ) followed by Podosphaera pannosa AB525937.2 (rDNA identity $=99.88 \%$ bitscore $=1,578$ ) and Podosphaera leucotricha JAATOF010000279.1 (mt-DNA identity $=99.9 \%$, bitscore $=5,723)$.

Phytohormones and horizontal gene transfer. The annotated mite assembly was searched for the following major plant/bacterial genes responsible for the production of phytohormones and enzymes involved in growth regulatory metabolism: 1-aminocyclopropane-1-carboxylic acid (ACC) deaminase, 2,3butanediol, abscisic acid, acetoin, auxin, brassinosteroids, cytokinin, ethylene, gibberellic acid, gibberellin, indole, indole-3-acetic acid (IAA), jasmonate, jasmonic acid, salicylic acid, strigolactone ${ }^{79-81}$.

TEM microscopy. Mites were fixed in $2.5 \%$ glutaraldehyde and $0.1 \mathrm{M}$ cacodilate buffer (Sigma C0250) for four hours, washed with the same buffer, treated with $1 \%$ tetroxide osmium for 1 hour, washed twice in distillated water, dehydrated in increasing ethanol series (30,50,70,96, 100\%) and embedded in SPURR resin (Sigma EM0300-1KT). Thin sections were prepared using a Leica EM UC7 ultramicrotome, contrasted with saturated solution of uranyl acetate 20 min and lead citrate for $5 \mathrm{~min}$, and photographed using a Jeol JEM-1400 electron microscope.

Fluorescence in situ hybridization (FISH). We used three oligonucleotide probes, each with a distinct fluorophore label: Eub 338 5'-GCTGCCTCC CGTAGGAGT-3' specific to Bacterial 16S rDNA gene (except for Planctomycetales и Verrucomicrobia), and two probes specific to Agrobacterium tumefaciens: 16S.1722F.Agr.tum 5'-TGTCCTTCAGTTAGGCTGGC-3' and 16S.907F.Agr.tum 5'-AATTAATACCGCATACGCCC-3'. Two fluorescent labels were used: CY3 (indocarocyanine 3) and FITC (5(6)-Carboxyfluorescein); DAPI (Invitrogen) was used for no probe control experiments. See additional detail in Supplementary Methods.

Data submitted to GenBank. Fragariocoptes setiger. Genomic assembly. GenBank BioSample id: SAMN13972306 accession: JAIFTH000000000.

Mite-associated organisms, metagenomic assembly. GenBank BioSample id: SAMN13981716, accession: JAALJN000000000.

Mite and associated organisms, metagenome, Illumina short reads. Short read archive (SRA) BioSample id: SAMN13981716, run selector: SRR11015813

Mite and associated organisms, metatranscriptome, Illumina short reads. Short read archive (SRA) BioSample id: SAMN13991554, run selector: SRR11026779.

Osperalycus tenerphagus AD1672, genomic assembly. DDBJ/ENA/GenBank accession JAGGCA000000000.

Page 9/16 
Speleorchestes sp. AD1671, genomic assembly. DDBJ/ENA/GenBank accession number JAGHQN000000000.

Wolbachia endosymbiont of Fragariocoptes setiger. Genomic assembly. GenBank accession: JAHRAF000000000, BioSample id: SAMN19370650.

\section{Declarations}

\section{Acknowledgements}

This study was supported by the Ministry of Science and Higher Education of the Russian Federation (agreement № 075-15-2020-922 "Agricultural technologies for the Future"). We thank Dr. Jeff Chang and Dr. Alexandra Weisberg (Oregon State University) for providing all databases used in the Vir-Search web service [http://gall-id.cgrb.oregonstate.edu/vir-finder.html], Sergey Diachkov (Tyumen State University, Russia) for help with the Gall-ID analysis and several GenBank submissions, and D. Hans Klompen (Ohio State University) who provided sequences of the two endeostigmatid mites. SJB was supported by Florida Department of Agriculture and Consumer Services, Division of Plant Industry.

\section{Author Contributions}

P.E.C. and P.B.K. designed the project; P.E.C. and S.S.P. collected Fragariocoptes specimens; S.J.B. collected endeostigmatid mite specimens; P.B.K. provided genomic sequences of Fragariocoptes, P.E.C., I.E.D. and L.A.L. provided transcriptomic sequences; A.E.V. and P.E.C. did FISH experiments, TEM microscopy, and confocal microscopy; P.B.K. designed FISH probes, did sample preparation for NGS sequencing of the endeostigmatid mites, did all analyses (except for GallID), and prepared all figures. P.B.K. and P.E.C. wrote the manuscript with contributions from other co-authors. All authors reviewed the manuscript.

\section{Competing interests}

The authors declare no competing interests.

\section{Additional Information}

Supplementary Information The online version contains supplementary material available at https://doi.org/\#\#\#\#.

Correspondence and requests for materials should be addressed to P.B.K. and P.E.C.

\section{References}

1. Schmidt, A. R. et al. Arthropods in amber from the Triassic period. Proc. Natl. Acad. Sci. U. S. A. 109, 14796-14801, doi:10.1073/pnas.1208464109 (2012).

2. de Lillo, E., Pozzebon, A., Valenzano, D. \& Duso, C. An intimate relationship between eriophyoid mites and their host plants - a review. Frontiers in Plant Science, 9, 1786 (2018).

3. Oldfield, G. N. \& Proeseler, G. in Eriophyoid Mites: Their Biology, Natural Enemies and Control. World Crop Pests Vol. 6 (eds E.E. Lindquist, J. Bruin, \& M.W. Sabelis) 259-275 (Elsevier, 1996).

4. Westphal, E. \& Manson, D. C. M. in Eriophyoid Mites: Their Biology, Natural Enemies and Control. World Crop Pests Vol. 6 (eds E.E. Lindquist, J. Bruin, \& M.W. Sabelis) 231-242 (Elsevier, 1996).

5. Lindquist, E. E. \& Amrine, J. W. Jr. in Eriophyoid Mites: Their Biology, Natural Enemies and Control. World Crop Pests Vol. 6 (eds E.E. Lindquist, J. Bruin, \& M.W. Sabelis) 33-87 (Elsevier, 1996).

6. Gupta, A. K. et al. Wheat streak mosaic virus alters the transcriptome of its vector, wheat curl mite (Aceria tosichella Keifer), to enhance mite development and population expansion. J. Gen. Virol, 100, 889-910 https://doi.org/10.1099/jgv.0.001256 (2019).

7. Chetverikov, P. E. et al. Molecular phylogeny of the phytoparasitic mite family Phytoptidae (Acariformes: Eriophyoidea) identified the female genitalic anatomy as a major macroevolutionary factor and revealed multiple origins of gall induction. Exp. Appl. Acarol, https://doi.org/10.1007/s10493-02000571-6 (2020).

8. Harris, M. O. \& Pitzschke, A. Plants make galls to accommodate foreigners: some are friends, most are foes. New Phytol, 225, 1852-1872 https://doi.org/10.1111/nph.16340 (2020).

9. Giron, D., Huguet, E., Stone, G. N. \& Body, M. Insect-induced effects on plants and possible effectors used by galling and leaf-mining insects to manipulate their host-plant. J. Insect Physiol, 84, 70-89 https://doi.org/10.1016/j.jinsphys.2015.12.009 (2016).

10. Andreas, P. et al. Cytokinins are abundant and widespread among insect species. Plants (Basel, Switzerland), 9, 208 https://doi.org/10.3390/plants9020208 (2020).

11. Gätjens-Boniche, 0 . The mechanism of plant gall induction by insects: revealing clues, facts, and consequences in a cross-kingdom complex interaction. Rev. Biol. Trop, 67, 1359-1382 (2019).

12. Tooker, J. F. \& Helms, A. M. Phytohormone dynamics associated with gall insects, and their potential role in the evolution of the gall-inducing habit. J. Chem. Ecol, 40, 742-753 https://doi.org/10.1007/s10886-014-0457-6 (2014).

13. Favery, B., Dubreuil, G., Chen, M. S., Giron, D. \& Abad, P. Gall-inducing parasites: Convergent and conserved strategies of plant manipulation by insects and nematodes. Annual Review of Phytopathology, 58, 1-22 https://doi.org/10.1146/annurev-phyto-010820-012722 (2020). 
14. Jameson, P. E. Cytokinins and auxins in plant-pathogen interactions - An overview. Plant. Growth Regul, 32, 369-380 doi:Doi 10.1023/A:1010733617543 (2000).

15. Zhu, J. et al. The bases of crown gall tumorigenesis. J. Bacteriol, 182, 3885-3895 (2000). doi:Doi 10.1128/Jb.182.14.3885-3895.2000

16. Akhtar, S. S., Mekureyaw, M. F., Pandey, C. \& Roitsch, T. Role of cytokinins for interactions of plants with microbial pathogens and pest insects. Front Plant Sci, 10, 1777 https://doi.org/10.3389/fpls.2019.01777 (2019).

17. De Lillo, E. \& Monfreda, R. 'Salivary secretions' of eriophyoids (Acari: Eriophyoidea): first results of an experimental model. Exp. Appl. Acarol, 34, 291-306 https://doi.org/10.1007/s10493-004-0267-6 (2004).

18. Paponova, S. S. et al. Gall mite Fragariocoptes setiger (Eriophyoidea) changes leaf developmental program and regulates gene expression in the leaf tissues of Fragaria viridis (Rosaceae). Ann. Appl. Biol, 172, 33-46 https://doi.org/10.1111/aab.12399 (2018).

19. Nishii, K., Wright, F., Chen, Y. Y. \& Moller, M. Tangled history of a multigene family: The evolution of Isopentenyltransferase genes. PLoS One, 13, https://doi.org/10.1371/journal.pone.0201198 (2018).

20. Siddique, S. et al. A parasitic nematode releases cytokinin that controls cell division and orchestrates feeding site formation in host plants. Proc. Natl. Acad. Sci. U. S. A. 112, 12669-12674, doi:10.1073/pnas.1503657112 (2015).

21. Eves-Van den Akker, S., Lilley, C. J., Yusup, H. B., Jones, J. T. \& Urwin, P. E. Functional C-Terminally Encoded Peptide (CEP) plant hormone domains evolved de novo in the plant parasite Rotylenchulus reniformis. Mol. Plant Pathol, 17, 1265-1275 https://doi.org/10.1111/mpp.12402 (2016).

22. Bird, D. M., Jones, J. T., Opperman, C. H., Kikuchi, T. \& Danchin, E. G. J. Signatures of adaptation to plant parasitism in nematode genomes., 142, S71-S84 https://doi.org/10.1017/S0031182013002163 (2015).

23. Hoffman, M. T., Gunatilaka, M. K., Wijeratne, K., Gunatilaka, L. \& Arnold, A. E. Endohyphal bacterium enhances production of indole-3-acetic acid by a foliar fungal endophyte. PLoS One, 8, e73132 https://doi.org/10.1371/journal.pone.0073132 (2013).

24. Zhang, H. et al. Dynamics and origin of cytokinins involved in plant manipulation by a leaf-mining insect. Insect Sci, 24, 1065-1078 https://doi.org/10.1111/1744-7917.12500 (2017).

25. Klimov, P. B. et al. Comprehensive phylogeny of acariform mites (Acariformes) provides insights on the origin of the four-legged mites (Eriophyoidea), a long branch. Mol. Phylogenet. Evol, 119, 105-117 https://doi.org/10.1016/j.ympev.2017.10.017 (2018).

26. Bolton, S. J., Chetverikov, P. E. \& Klompen, H. Morphological support for a clade comprising two vermiform mite lineages: Eriophyoidea (Acariformes) and Nematalycidae. (Acariformes) Systematic \& Applied Acarology, 22, 1096-1131 (2017).

27. Lindquist, E. E. in Eriophyoid Mites: Their Biology, Natural Enemies and Control. World Crop Pests Vol. 6 (eds E.E. Lindquist, J. Bruin, \& M.W. Sabelis) 301327 (Elsevier, 1996).

28. Dubinin, V. B. in Fundamentals of Paleontology. Volume 9. Arthropoda, Tracheata, Chelicerata. [Osnovy paleontoligii. A manual for paleontologists and geologists of the USSR, translated by IPST Staff] (ed B.B. Rohdendorf) 681-722(Smithsonian Institution Libraries and National Science Foundation, 1962).

29. Hirst, S. On some arachnid remains from the Old Red Sandstone (Rhynie Chert bed, Aberdeenshire). Annals and Magazine of Natural History, series 912 , 455-474 + 455 plates(1923).

30. Woodcroft, B. \& Singlem Available from: https://github.com/wwood/singlem/ (accessed January 10, 2020). (2019).

31. Xue, X. F., Dong, Y., Deng, W., Hong, X. Y. \& Shao, R. The phylogenetic position of eriophyoid mites (superfamily Eriophyoidea) in Acariformes inferred from the sequences of mitochondrial genomes and nuclear small subunit (18S) rRNA gene. Mol. Phylogenet. Evol, 109, 271-282

https://doi.org/10.1016/j.ympev.2017.01.009 (2017).

32. Li, H. S. et al. Identification of two lineages of host-associated eriophyoid mites predisposed to different levels of host diversification. Mol. Phylogenet. Evol, 105, 235-240 (2016).

33. Arribas, P. et al. Mitochondrial metagenomics reveals the ancient origin and phylodiversity of soil mites and provides a phylogeny of the Acari. Mol. Biol. Evol, https://doi.org/10.1093/molbev/msz255 (2019).

34. Xue, X. F., Guo, J. F., Dong, Y., Hong, X. Y. \& Shao, R. Mitochondrial genome evolution and tRNA truncation in Acariformes mites: new evidence from eriophyoid mites. Sci. Rep, 6, 18920 (2016).

35. Greenhalgh, R. et al. Genome streamlining in a minute herbivore that manipulates its host plant. eLife, 9, e56689 https://doi.org/10.7554/eLife.56689 (2020).

36. Gordon, J. E. \& Christie, P. J. The Agrobacterium Ti plasmids. Microbiology Spectrum, 2, https://doi.org/10.1128/microbiolspec.PLAS-0010-2013 (2014).

37. Lin, J. S., Ma, L. S. \& Lai, E. M. Systematic dissection of the Agrobacterium type VI secretion system reveals machinery and secreted components for subcomplex formation. PLoS One, 8, e67647 https://doi.org/10.1371/journal.pone.0067647 (2013).

38. Noutoshi, Y. et al. Complete genome sequence data of nonpathogenic strain Rhizobium vitis VAR03-1, a biological control agent for grapevine crown gall disease. Mol. Plant. Microbe Interact, 33, 1451-1453 https://doi.org/10.1094/MPMI-07-20-0181-A (2020).

39. Andrews, J. H. \& Harris, R. F. The ecology and biogeography of microorganisms on plant surfaces. Annual Review of Phytopathology, 38, 145-180 https://doi.org/10.1146/annurev.phyto.38.1.145 (2000).

40. Lopez-Fernandez, S., Mazzoni, V., Pedrazzoli, F., Pertot, I. \& Campisano, A. A phloem-feeding Insect transfers bacterial endophytic communities between grapevine plants. Front. Microbiol, 8, 834 https://doi.org/10.3389/fmicb.2017.00834 (2017).

41. Chevalier, S. et al. Structure, function and regulation of Pseudomonas aeruginosa porins. FEMS Microbiol. Rev, 41, 698-722 https://doi.org/10.1093/femsre/fux020 (2017).

Page $11 / 16$ 
42. Moreno-Perez, A. et al. Host range determinants of Pseudomonas savastanoi pathovars of woody hosts revealed by comparative genomics and crosspathogenicity tests. Frontiers in Plant Science, 11, 973 https://doi.org/10.3389/fpls.2020.00973 (2020).

43. Mendoza, G., Sánchez-Tafolla, L. \& Trigos, Ã. Oxidative foliar photo-necrosis produced by the bacteria Pseudomonas cedrina. Electron. J. Biotechnol, 44, 14-18 https://doi.org/10.1016/j.ejbt.2020.01.007 (2020).

44. Young, J. M. Taxonomy of Pseudomonas syringae. Journal of Plant Pathology, 92, S5-S14 (2010).

45. Qi, M., Wang, D., Bradley, C. A. \& Zhao, Y. Genome sequence analyses of Pseudomonas savastanoi pv. glycinea and subtractive hybridization-based comparative genomics with nine pseudomonads. PLoS One, 6, e16451 https://doi.org/10.1371/journal.pone.0016451 (2011).

46. Caballo-Ponce, E. et al. Knots untie: Molecular determinants involved in knot formation induced by Pseudomonas savastanoi in woody hosts. Frontiers in Plant Science, 8, 1089 (2017).

47. Gavini, F. et al. Transfer of Enterobacter agglomerans (Beijerinck 1888) Ewing and Fife 1972 to Pantoea gen. nov. as Pantoea agglomerans comb. nov. and description of Pantoea dispersa sp. nov. International Journal of Systematic and Evolutionary Microbiology, 39, 337-345(1989).

48. Guo, M., Manulis, S., Mor, H. \& Barash, I. The presence of diverse IS elements and an avrPphD homologue that acts as a virulence factor on the pathogenicity plasmid of Erwinia herbicola pv. gypsophilae. Molecular Plant-Microbe Interactions ${ }^{\circledR}, 15,709-716$ https://doi.org/10.1094/MPMI.2002.15.7.709 (2002).

49. Zhang, Z. \& Nan, Z. Erwinia persicina, a possible new necrosis and wilt threat to forage or grain legumes production. Eur. J. Plant Pathol, 139, 349-358 https://doi.org/10.1007/s10658-014-0390-0 (2014).

50. Glassing, A., Dowd, S. E., Galandiuk, S., Davis, B. \& Chiodini, R. J. Inherent bacterial DNA contamination of extraction and sequencing reagents may affect interpretation of microbiota in low bacterial biomass samples. Gut Pathog, 8, https://doi.org/10.1186/s13099-016-0103-7 (2016).

51. Kaiser, W., Huguet, E., Casas, J., Commin, C. \& Giron, D. Plant green-island phenotype induced by leaf-miners is mediated by bacterial symbionts. Proceedings of the Royal Society B: Biological Sciences 277, 2311-2319, doi:10.1098/rspb.2010.0214 (2010).

52. Gutzwiller, F., Dedeine, F., Kaiser, W., Giron, D. \& Lopez-Vaamonde, C. Correlation between the green-island phenotype and Wolbachia infections during the evolutionary diversification of Gracillariidae leaf-mining moths. Ecol. Evol, 5, 4049-4062 https://doi.org/10.1002/ece3.1580 (2015).

53. Barr, K. L., Hearne, L. B., Briesacher, S., Clark, T. L. \& Davis, G. E. Microbial symbionts in insects influence down-regulation of defense genes in maize. PLoS One, 5, e11339 https://doi.org/10.1371/journal.pone.0011339 (2010).

54. Alfano, J. R. \& Collmer, A. Type III secretion system effector proteins: double agents in bacterial disease and plant defense. Annu Rev Phytopathol, 42, 385-414 https://doi.org/10.1146/annurev.phyto.42.040103.110731 (2004)

55. Groen, S. C. et al. Pseudomonas syringae enhances herbivory by suppressing the reactive oxygen burst in Arabidopsis. J. Insect Physiol, 84, $90-102$ https://doi.org/10.1016/j.jinsphys.2015.07.011 (2016).

56. Eberl, L. \& Vandamme, P. Members of the genus Burkholderia: good and bad guys. F1000Res 5, doi:10.12688/f1000research.8221.1 (2016).

57. Goto, M. \& Kuwata, H. Rhizobacter daucus gen. nov., sp. nov., the causal agent of carrot bacterial gall. Int. J. Syst. Evol. Microbiol, 38, 233-239 (1988).

58. Normand, P. et al. Frankia canadensis sp. nov., isolated from root nodules of Alnus incana subspecies rugosa. Int. J. Syst. Evol. Microbiol, 68, 3001-3011 https://doi.org/10.1099/ijsem.0.002939 (2018).

59. Benson, D. R. \& Silvester, W. B. Biology of Frankia strains, actinomycete symbionts of actinorhizal plants. Microbiol. Rev, 57, 293-319 (1993).

60. Sugio, A. et al. Diverse targets of phytoplasma effectors: from plant development to defense against insects. Annual Review of Phytopathology, 49, 175195 https://doi.org/10.1146/annurev-phyto-072910-095323 (2011).

61. Sugio, A., Kingdom, H. N., MacLean, A. M., Grieve, V. M. \& Hogenhout, S. A. Phytoplasma protein effector SAP11 enhances insect vector reproduction by manipulating plant development and defense hormone biosynthesis. Proc. Natl. Acad. Sci. U. S. A. 108, E1254-1263, doi:10.1073/pnas.1105664108 (2011).

62. MacLean, A. M. et al. Phytoplasma effector SAP54 hijacks plant reproduction by degrading MADS-box proteins and promotes insect colonization in a RAD23-dependent manner. PLoS Biol, 12, e1001835 https://doi.org/10.1371/journal.pbio.1001835 (2014).

63. Bordenstein, S. R. et al. Parasitism and mutualism in Wolbachia: What the phylogenomic trees can and cannot say. Mol. Biol. Evol, 26, 231-241 https://doi.org/10.1093/molbev/msn243 (2009).

64. Zeidan, M. \& Czosnek, H. Acquisition and transmission of Agrobacterium by the whitefly Bemisia tabaci. Molecular Plant-Microbe Interactions Journal, 7, 792-798 https://doi.org/10.1094/mpmi-7-0792 (1994).

65. Hammer, T. J. et al. Are bacterial symbionts associated with gall induction in insects? Arthropod-Plant Interactions, 15, 1-12 https://doi.org/10.1007/s11829-020-09800-6 (2021).

66. Nurk, S., Meleshko, D., Korobeynikov, A. \& Pevzner, P. A. metaSPAdes: a new versatile metagenomic assembler. Genome Res, 27, 824-834 https://doi.org/10.1101/gr.213959.116 (2017).

67. Kang, D. D., Froula, J., Egan, R. \& Wang, Z. MetaBAT, an efficient tool for accurately reconstructing single genomes from complex microbial communities. PeerJ, 3, e1165 https://doi.org/10.7717/peerj.1165 (2015).

68. Buchfink, B., Xie, C. \& Huson, D. H. Fast and sensitive protein alignment using DIAMOND. Nature Methods, 12, 59-60 https://doi.org/10.1038/nmeth.3176 (2015).

69. Cantarel, B. L. et al. MAKER: an easy-to-use annotation pipeline designed for emerging model organism genomes. Genome Res, 18, 188-196 https://doi.org/10.1101/gr.6743907 (2008). 
70. Nguyen, L. T., Schmidt, H. A., von Haeseler, A. \& Minh, B. Q. IQ-TREE: a fast and effective stochastic algorithm for estimating maximum-likelihood phylogenies. Mol. Biol. Evol, 32, 268-274 https://doi.org/10.1093/molbev/msu300 (2015).

71. Seppey, M., Manni, M. \& Zdobnov, E. M. BUSCO: assessing genome assembly and annotation completeness. Methods Mol. Biol. 1962, 227-245, doi:10.1007/978-1-4939-9173-0_14 (2019).

72. Inouye, M. et al. SRST2: Rapid genomic surveillance for public health and hospital microbiology labs. Genome Med, 6, https://doi.org/10.1186/s13073014-0090-6 (2014).

73. Davis, E. W., Weisberg, A. J., Tabima, J. F., Grunwald, N. J. \& Chang, J. H. Gall-ID: tools for genotyping gall-causing phytopathogenic bacteria. PeerJ, 4, https://doi.org/10.7717/peerj.2222 (2016).

74. Wood, D. E. \& Salzberg, S. L. Kraken: ultrafast metagenomic sequence classification using exact alignments. Genome Biol, 15, https://doi.org/10.1186/gb2014-15-3-r46 (2014).

75. Peabody, M. A., Van Rossum, T., Lo, R. \& Brinkman, F. S. L. Evaluation of shotgun metagenomics sequence classification methods using in silico and in vitro simulated communities. BMC Bioinformatics, 16, 362 https://doi.org/10.1186/s12859-015-0788-5 (2015).

76. Lu, J., Breitwieser, F. P., Thielen, P. \& Salzberg, S. L. Bracken: estimating species abundance in metagenomics data. Peerj Computer Science, https://doi.org/10.7717/peerj-cs.104 (2017).

77. Chen, C. et al. TBtools: An integrative toolkit developed for interactive analyses of big biological data. Mol. Plant, 13, 1194-1202 https://doi.org/10.1016/j.molp.2020.06.009 (2020).

78. Steen, A. D. et al. High proportions of bacteria and archaea across most biomes remain uncultured. The ISME Journal, 13, 3126-3130 https://doi.org/10.1038/s41396-019-0484-y (2019).

79. Taghavi, S. et al. Genome survey and characterization of endophytic bacteria exhibiting a beneficial effect on growth and development of poplar trees. Appl. Environ. Microbiol, 75, 748-757 https://doi.org/10.1128/AEM.02239-08 (2009).

80. Shi, T. Q. et al. Microbial production of plant hormones: Opportunities and challenges., 8, 124-128 https://doi.org/10.1080/21655979.2016.1212138 (2017).

81. Ryu, C. M. et al. Bacterial volatiles promote growth in Arabidopsis. Proc. Natl. Acad. Sci. U. S. A. 100, 4927-4932, doi:10.1073/pnas.0730845100 (2003).

\section{Figures}

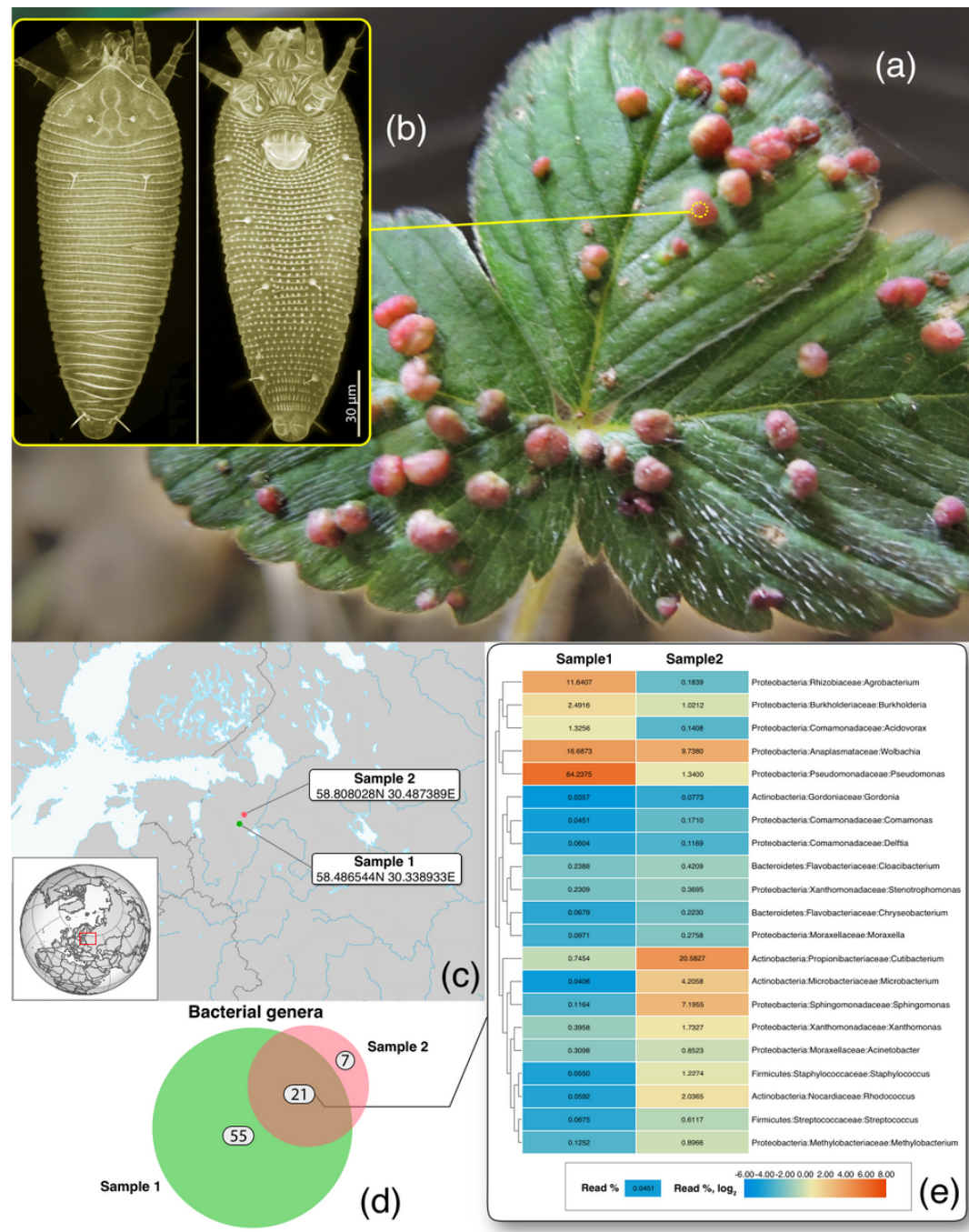

Page 13/16 


\section{Figure 1}

Galls on leaves of the creamy strawberry Fragaria viridis (a) induced by the mite Fragariocoptes setiger (b); mite collection localities, samples 1 and 2 (c); Bacterial taxonomic richness in samples 1 and 2, the number of unique bacterial genera in each sample and in their intersection is shown as a Venn diagram (d), k-mer-based taxonomic classification was done in Kraken using a normalized abundance threshold of $\geq 0.0338 \%$; there was a total of $49,514,852$ and $3,830,185$ classified bacterial reads in samples 1 and 2, respectively; detailed taxonomic classification and abundance estimates are given in Supplementary Table S2 and visualized in Supplementary Fig. S1; abundance of bacterial genera in the intersection of samples 1 and 2 (e), abundance values are percentages of classified reads, while the heatmap colors are based on log2-transformed abundance values.

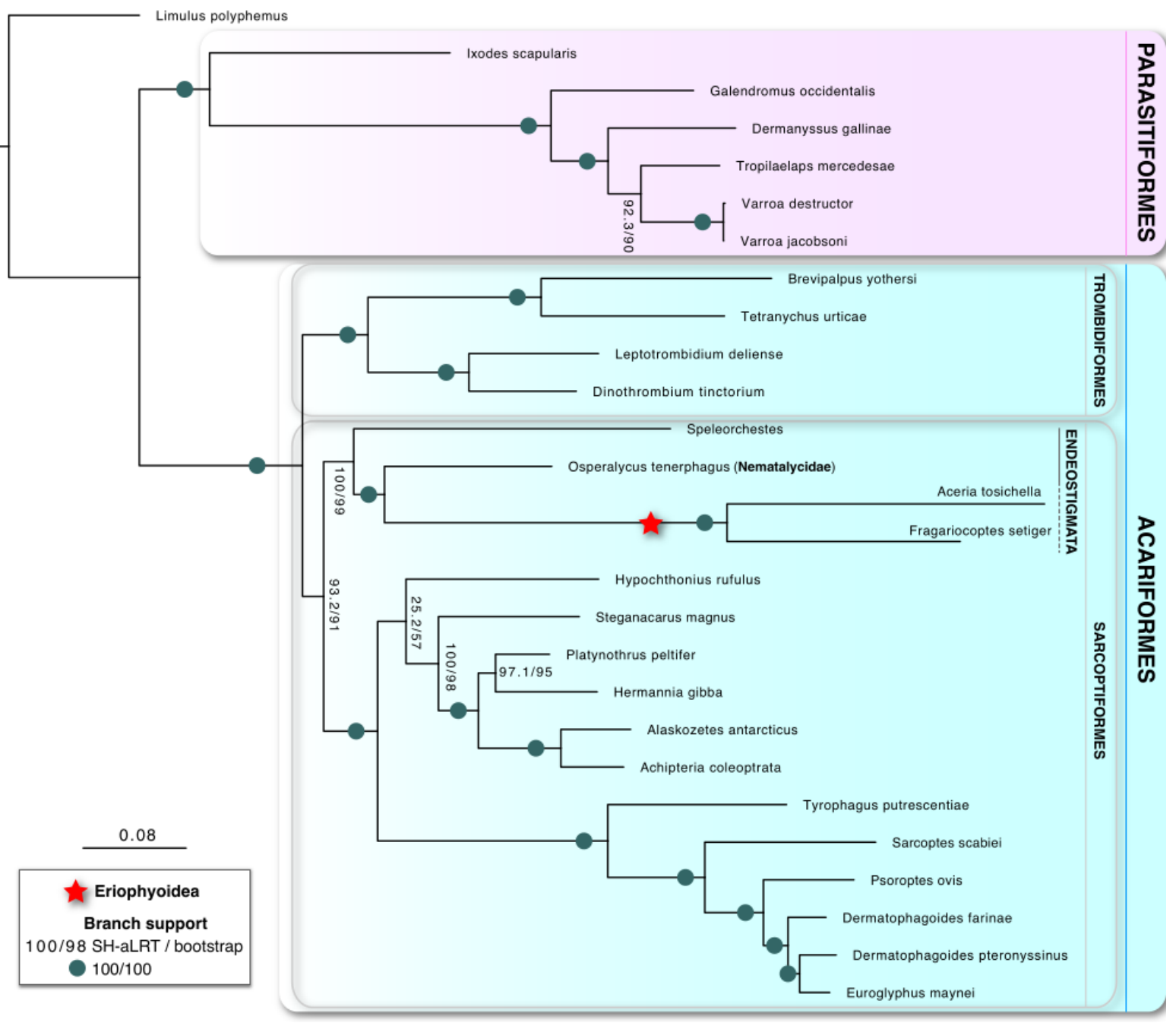

\section{Figure 2}

Relationships of parasitiform and acariform mites. Phylogenomic inference was undertaken using a Maximum likelihood framework in IQ-TREE based on 90 orthologous proteins. 


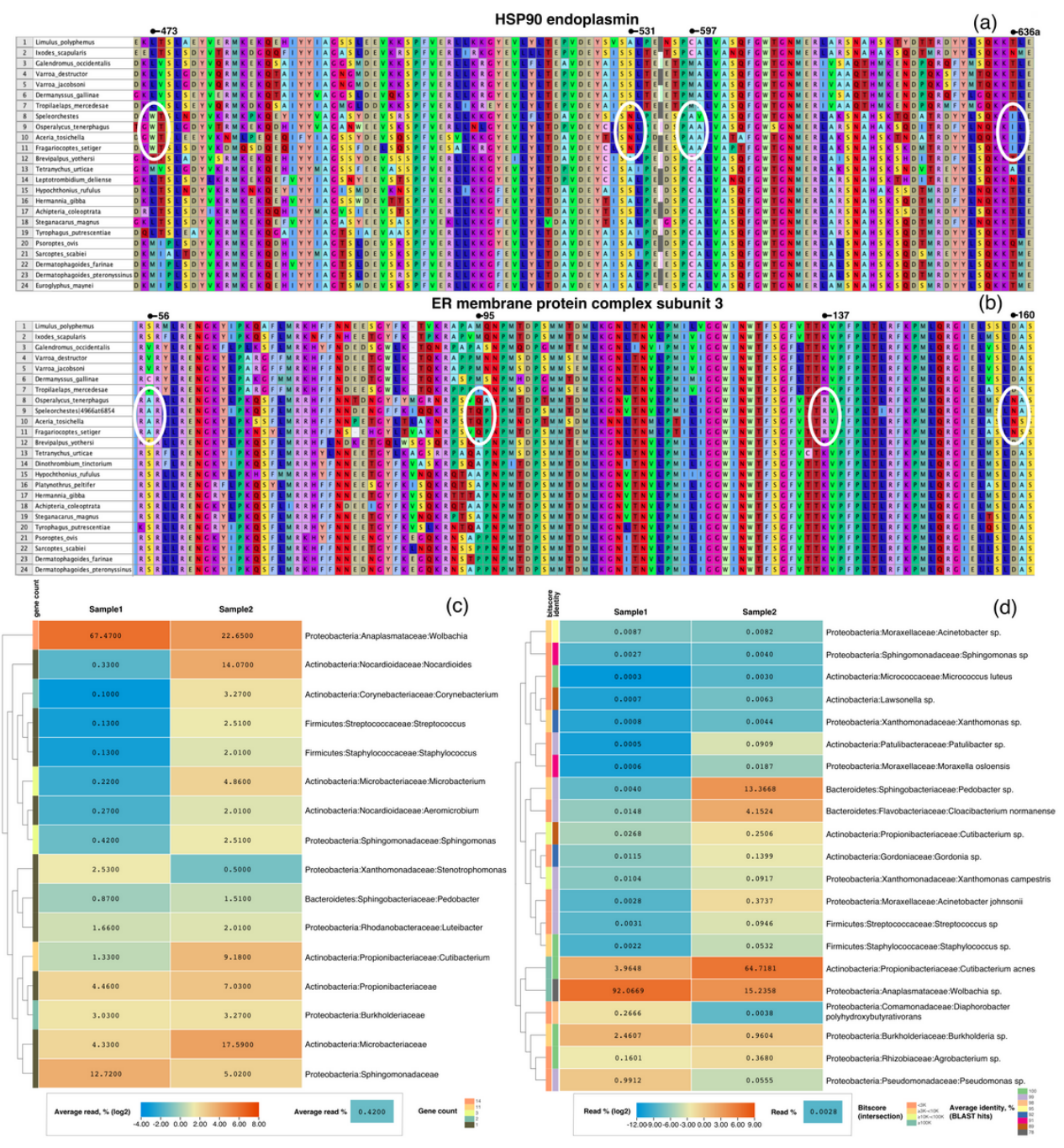

Figure 3

Select molecular autapomorphies for the Endeostigmata, including Eriophyoidea, in two proteins (a-b): HSP90 endoplasmin (a) and ER membrane protein complex subunit 3 (b); amino acid alignment coordinates are given for the Limulus polyphemus reference proteins (XP_013791125.1, XP_022251172.1). Bacterial OTUs shared between samples 1 and 2 as identified by mapping metagenomic reads onto a set of 14 single-copy genes in singleM (c); for each OTU, a gene count returning matches in both samples is given. The heatmap gives read percentages in the intersection, while its colors are based on log2 of these values. Normalization was done only for OTUs present in the intersection. Bacterial OTUs shared among samples 1 and 2 as identified via intersection of two metagenomic assemblies (d); for each OTU, intersection bitscore, and average sequence identity (BLAST using GenBank nucleotide database) are given. The heatmap gives normalized read percentages, while its colors are based on log2 of these values. Normalization was done only for OTUs present in the intersection. Only alignments having a bitscore $\geq 1500$ are shown. 


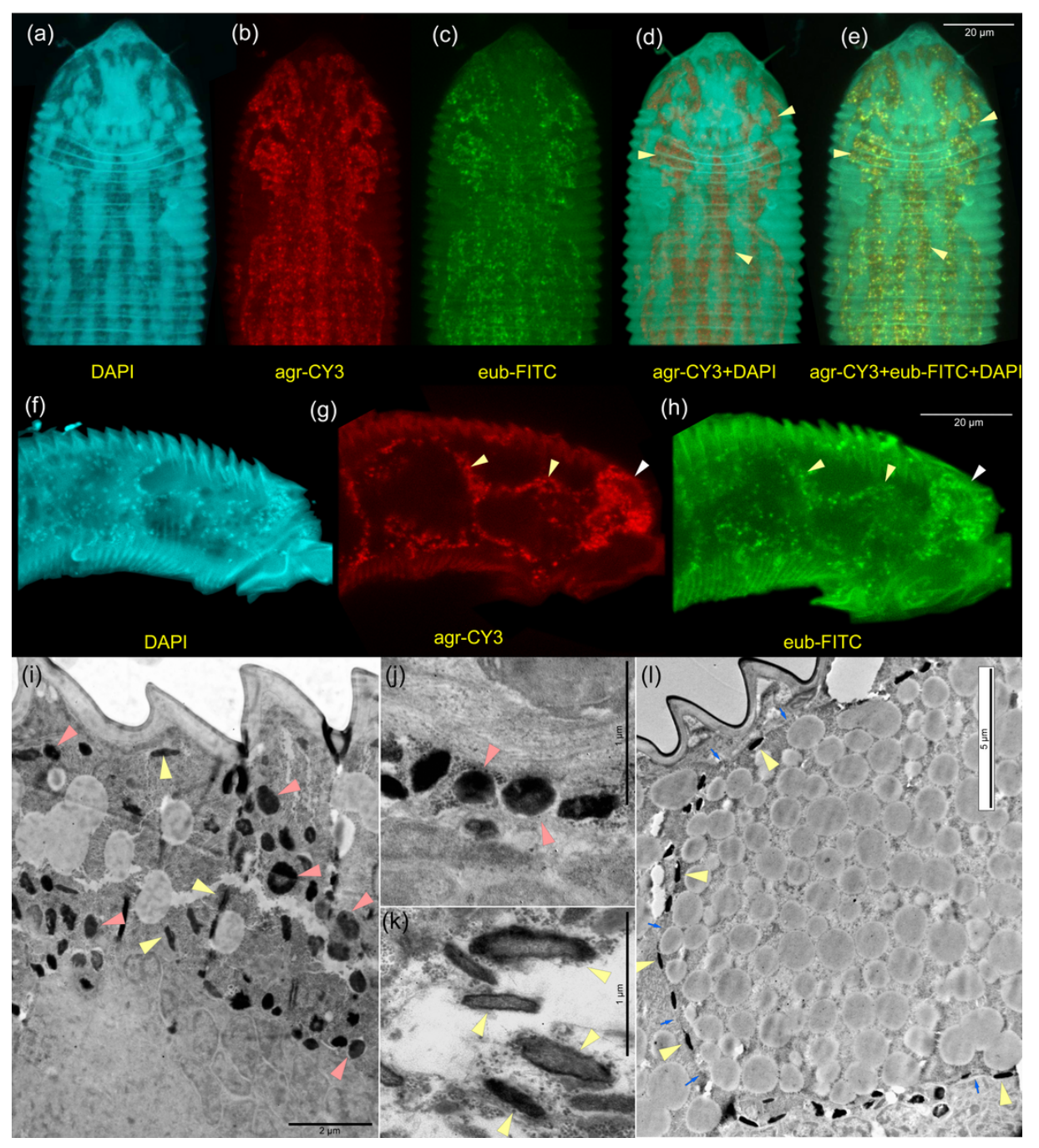

\section{Figure 4}

Endosymbiotic bacteria of the mite Fragariocoptes setiger, fluorescence in situ hybridization (FISH) with different fluorophores and oligonucleotide probes (ah) and TEM microscopy (i-l). Mite anterodorsal (a-e) and anterolateral parts ( $\mathrm{f}-\mathrm{h}$ ); intermuscular bacteria (d-e, yellow arrowheads), bacteria surrounding gigantic parenchymal cells (g-h, yellow arrowheads) and salivary glands (g-h, white arrowheads); DAPI+no probe (a,f); CY3+16S.1722F.Agr.tum (b,g); FITC+ Eub338 (c,g); CY3+16S.1722F.Agr.tum, DAPI (d); CY3+16S.1722F.Agr.tum, FITC+eub338, DAPI (e). Bacterial morphotype 1 (Wolbachia) (i-j, red arrowheads), and bacterial morphotype 2 (yellow arrowheads) (k-l, yellow arrowheads) in various locations inside the mite: mid-lateral opisthosoma with saw-like cuticle and underlying tissues are visible (i), same as previous, gigantic parenchymal cell (fat body) is shown and traced by small blue arrows ( $\mathrm{l}$ ), spaces between the fat body and the gut $(j, k)$.

\section{Supplementary Files}

This is a list of supplementary files associated with this preprint. Click to download.

- FigS1KrakenBacteriaabundancethresholdge0.0338.AllBacteriaBlueyellowred.pdf

- FigS2KrakenAllabundancethresholdge0.0050.AllTaxaBlueyellowred.pdf

- TableS1Qualityassessmentofthemitemetatranscriptome.docx

- TableS2KrakenBacteriaabundancethresholdge0.0338.xlsx

- TableS3KrakenAllabundancethresholdge0.0005.xlsx

- Tables4KrakenAllclassificationandabundance.xIsx

- TableS5SinglemclassificattionclusteredOTUs.xIsx

- OSupplementaryMethods.docx

- FileS14runconcatenateBUSCOsfilterv4.sh.txt

- Files227genomeconcatenatedaamatrixandparitionsRaw.txt

- FileS327genomeconcatenatedaamatrixwithpartitionsEdited.nex 